\title{
Diferenciação institucional na certificação de produtos orgânicos: uma comparação dos Organismos Participativos de Avaliação da Conformidade no estado do Rio Grande do Sul
}

\author{
Institutional differentiation in the certification of organic products: a \\ comparison of the Participatory Conformity Assessment Bodies in the state \\ of Rio Grande do Sul
}

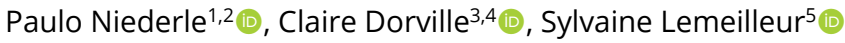 \\ 'Programa de Pós-graduação em Sociologia (PPGS), Universidade Federal do Rio Grande do Sul (UFRGS), Porto Alegre (RS), \\ Brasil. E-mail: paulo.niederle@ufrgs.br \\ ${ }^{2}$ Programa de Pós-graduação em Desenvolvimento Rural (PGDR), Universidade Federal do Rio Grande do Sul (UFRGS), Porto \\ Alegre (RS), Brasil. \\ ${ }^{3}$ Université de Montpellier, Montpellier, France. E-mail: claire.dorville@cirad.fr \\ ${ }^{4}$ Centre de Cooperation Internationale en Recherche Agronomique pour le Développement (CIRAD), Montpellier, France. \\ ${ }^{5}$ UMR Moisa, Centre de Cooperation Internationale en Recherche Agronomique pour le Développement (CIRAD), Montpellier, \\ France. E-mail: sylvaine.lemeilleur@cirad.fr
}

Como citar: Niederle, P., Dorville, C., \& Lemeilleur, S. (2021). Diferenciação institucional na certificação de produtos orgânicos: uma comparação dos Organismos Participativos de Avaliação da Conformidade no estado do Rio Grande do Sul. Revista de Economia e Sociologia Rural, 59(2), e224827. https://doi.org/10.1590/1806-9479.2021.224827

\begin{abstract}
Resumo: Este artigo analisa os fatores de diferenciação institucional nos processos de certificação participativa de produtos orgânicos. Realizada junto aos Organismos Participativos de Avaliação da Conformidade (OPAC) que operam no estado do Rio Grande do Sul, a pesquisa visava inicialmente responder se eles estariam convergindo para formatos organizacionais e estratégias similares. A hipótese inicial sugeria o isomorfismo desses organismos em virtude de pressões institucionais coercitivas, normativas e miméticas. No entanto, devido à rejeição da hipótese inicial, buscou-se, então, identificar os fatores que produzem diferenciação institucional. Foram examinados instrumentos normativos que regulam a certificação orgânica, os documentos internos de gestão dos OPACs, transcrições de entrevistas individuais e coletivas com stakeholders e anotações de observações das reuniões e procedimentos de certificação. Os resultados demonstram processos de dissociação (decoupling) impulsionados por três fatores principais: ambiguidade e heterogeneidade do ambiente institucional, resistência dos atores às pressões isomórficas e dinâmicas internas de poder relacionadas com o formato de participação social em cada OPAC.
\end{abstract}

Palavras-chave: instituições, organizações, certificação, agricultura, orgânicos.

\begin{abstract}
This article analyzes the factors of institutional differentiation in the processes of participatory certification of organic products. The research conducted with the participatory conformity assessment bodies (OPACs) in the state of Rio Grande do Sul, initially aimed to answer whether they were converging to similar organizational structures and strategies. The initial hypothesis suggested the isomorphism of these organizations due to coercive, normative and mimetic institutional pressures. However, due to the rejection of the initial hypothesis, it sought to identify the factors that produce institutional differentiation. Normative instruments that regulate organic certification, OPACs' internal management documents, transcripts of individual and collective interviews with stakeholders, and notes issues from the observations of meetings and certification procedures were examined. Results demonstrate decoupling processes driven by three main factors: ambiguity and heterogeneity of the institutional environment, resistance of the actors to isomorphic pressures, and internal power dynamics related to the format of social participation in each OPAC.
\end{abstract}

Keywords: institutions, organizations, certification, agriculture, organic. 


\section{Introdução}

A expansão do mercado de produtos orgânicos tem sido acompanhada por uma preocupação em viabilizar o acesso a ele para agricultores que não têm condições de arcar com os custos dos sistemas privados de certificação. Em virtude disso, é cada vez maior o interesse internacional pela experiência brasileira de construção de mecanismos alternativos de avaliação da conformidade orgânica (Loconto et al., 2016; Niederle et al., 2020). O país é um dos poucos do mundo em que o Estado reconhece formalmente os sistemas participativos de garantia (Loconto \& Hatanaka, 2018). Além da certificação por terceira parte, a norma brasileira prevê a atuação de Organismos Participativos de Avaliação da Conformidade (OPACs) - os quais se constituem de organizações formais que coordenam processos de controle cruzado entre grupos de agricultores - e de Organizações de Controle Social (OCS) - as quais atestam (sem certificação) a conformidade por meio de sistemas de autocontrole internos aos grupos.

Em abril de 2020, o Ministério da Agricultura, Pecuária e Abastecimento (Mapa) contabilizava quase 22 mil registros de pessoas físicas e jurídicas para produção e comercialização de alimentos orgânicos no Brasil. Deste total, 9,6 mil estavam associados à certificação por auditoria externa, 4,6 mil referiam-se a registros de OCS e 7,6 mil diziam respeito à certificação participativa, os quais eram administrados por 26 OPACs. Nos três estados da Região Sul do país, onde a certificação participativa se desenvolveu mais rapidamente nos últimos anos (Isaguirre \& Passos, 2013), havia 5,4 mil registros nesta categoria. Isto significa que, nesta região, a certificação participativa era, inclusive, mais disseminada do que a auditoria externa de terceira parte, a qual contabilizava 3,2 mil registros. O mesmo ocorre no Rio Grande do Sul, onde quatro OPACs (Ecovida, Rama, Litoral Norte e Coceargs) congregam 2,2 mil produtores, frente a 858 que utilizam certificadoras. ${ }^{1}$

Inúmeros estudos já analisaram as similaridades e diferenças entre esses sistemas de avaliação da conformidade orgânica (Caldas et al., 2012; Niederle \& Radomsky, 2017; Medaets \& Cechin, 2019). Eles demonstram que a certificação participativa foi construída e disseminada por organizações do movimento agroecológico para se contrapor à exclusão dos agricultores familiares decorrente dos custos da auditoria de terceira parte, sobretudo quando esta é realizada por empresas privadas (Medaets et al., 2020). Outro motivo seria a contraposição à perspectiva excessivamente técnico-produtiva da certificação por auditoria, a qual desconsideraria os fatores culturais implicados na transição agroecológica, em particular os processos de aprendizagem social necessários não apenas ao manejo ecológico dos agroecossistemas, mas, principalmente, à inserção dos agricultores nos mercados (Radomsky, 2015; Niederle \& Wesz Junior, 2018)

São mais raros os estudos que comparam as estruturas organizacionais, os modos de funcionamento e os resultados produzidos pelos OPACs no Brasil (Caldas et al., 2012; Niederle et al., 2020). Além disso, nenhum deles se debruçou sobre uma questão recorrente na literatura internacional sobre orgânicos, qual seja: a existência de um processo de uniformização das estruturas e procedimentos de certificação como efeito da difusão internacional de regras e padrões (Fouilleux, 2013; Boström, 2006; Hatanaka et al., 2005; Lemeilleur \& Allaire, 2018). Segundo Fouilleux \& Loconto (2017), este processo tem sido impulsionado pela concentração e transnacionalização das empresas certificadoras. Como consequência, ao invés de sistemas heterogêneos e fortemente vinculados aos locais de produção e consumo - como defendem as organizações promotoras da agroecologia - este processo estimularia a padronização e a convencionalização dos orgânicos (Buck et al., 1997; Allen \& Kovach, 2000).²

\footnotetext{
1 Em virtude da disseminação da certificação participativa, que permite venda indireta (com intermediários), o número de registros via OCS é pequeno no Rio Grande do Sul (335) e na Região Sul como um todo (396).

2 O debate da convencionalização é vastamente conhecido nesta literatura. Nos anos 1990, ele focalizou o interesse de empresários agrícolas na produção orgânica como uma nova oportunidade de negócios e esse processo foi entendido como a apropriação parcial de insumos naturais e práticas sustentáveis em sistemas agrícolas convencionais. Pesquisas subsequentes demonstraram que esta dinâmica de apropriação se estendia para o restante da cadeia de valor, haja vista a concentração do processamento e da distribuição de alimentos orgânicos pelas empresas líderes. Como um dos principais impulsionadores desse processo é a produção de normas e padrões, ele também foi associado aos efeitos da certificação.
} 
Essas mudanças podem ser interpretadas a partir do conceito de "isomorfismo institucional", o qual sugere que organizações (certificadoras) adotam e disseminam formatos e condutas análogos em virtude de pressões advindas do ambiente institucional em que atuam (Meyer \& Rowan, 1977; Hannan \& Freeman, 1977; Dimaggio \& Powell, 1983). A partir desta chave analítica, este artigo inicialmente buscou responder a seguinte questão de pesquisa: estão os OPACs também convergindo para estruturas e condutas similares? A hipótese inicial da pesquisa sugeria um processo de isomorfismo institucional que, em grande medida, revelaria uma espécie de "cópia" do "modelo original" da Associação Ecovida de Certificação Participativa, o qual foi utilizado como referência para a construção da legislação brasileira. Para testar esta hipótese, o primeiro passo foi comparar o "modelo Ecovida" com aquele adotado pelos outros três OPACs (Rama, Litoral Norte e Coceargs) que atuam no estado do Rio Grande do Sul. A escolha de organizações do mesmo estado visava reduzir os possíveis efeitos da inserção dos atores em diferentes contextos institucionais.

No entanto, como veremos no artigo, contrariando a expectativa inicial os resultados apontaram para a predominância de processos de diferenciação institucional. Ainda que pressões isomórficas tenham sido identificadas e, do ponto de vista formal, determinados elementos estruturais são similares entre os OPACs, inúmeras diferenças contrariam a ideia de difusão e cópia dos mesmos formatos organizacionais e condutas. Em virtude disso, a pesquisa voltou-se para uma segunda questão: Quais são os fatores que produzem a diferenciação institucional? A nova hipótese sugeria que a diferenciação era um efeito direto da constituição dos espaços de participação social para a gestão dos OPACs. Entretanto, além das dinâmicas internas de poder que estão, em alguma medida, relacionadas à participação social, os resultados demonstram que outros dois fatores também são centrais para explicar os processos de "dissociação" (Boxenbaum \& Jonsson, 2017): a ambiguidade e heterogeneidade do ambiente institucional e a resistência dos atores às pressões isomórficas. ${ }^{3}$

Os dados foram coletados em 2018 a partir de quatro fontes: (i) documentos públicos sobre a regulamentação da certificação orgânica (Leis, Decretos e Instruções Normativas); (ii) documentos internos dos OPACs (Estatutos, Regimentos, Planos de Manejo, Manuais de Procedimentos); (iii) 31 entrevistas individuais e coletivas com gestores públicos, agricultores, lideranças sociais e técnicos; e (iv) observação de reuniões e procedimentos de certificação. A análise se concentrou em dois níveis articulados. O primeiro era o do ambiente institucional, com especial atenção aos dispositivos normativos da certificação. O segundo era o nível do arranjo organizacional e das condutas dos OPACs. Inicialmente, identificamos as relações entre estes níveis, destacando como as "regras do campo" orientam os atores e, ao mesmo tempo, são traduzidas e recursivamente alteradas por eles. Em seguida, comparamos como os diferentes OPACs se posicionam frente ao ambiente institucional e aos demais atores. Para tanto, destacamos os elementos organizacionais mais relevantes nas estratégias de certificação participativa, tais como: formato e papel dos grupos; articulação com outras organizações; presença de mediadores sociais; formas diferenciadas de tradução das normas; espaços de decisão e mecanismos de coordenação; e valores sociais predominantes.

O artigo está estruturado em quatro seções além desta introdução. A próxima seção discute o referencial teórico. Em seguida é apresentada a análise das estruturas organizacionais e condutas de cada OPAC. A seção subsequente interpreta o processo de dissociação que leva à diferenciação institucional. As considerações finais destacam as principais conclusões e apontam sugestões para uma agenda de pesquisa.

\section{Isomorfismo, dissociação e diferenciação institucional}

Nas duas últimas décadas, o conceito de isomorfismo institucional se tornou o núcleo principal da teoria mais conhecida nas ciências sociais para explicar as similaridades entre as organizações. Inicialmente proposta por Meyer \& Rowan (1977) e Hannan \& Freeman

\footnotetext{
${ }^{3}$ Os autores agradecem as sugestões dos pareceristas anônimos da RESR na construção desta interpretação.
} 
(1977) e posteriormente aprimorada e difundida por Dimaggio \& Powell (1983), esta teoria sugere que, para além da concorrência capitalista nos mercados (isomorfismo competitivo), existem fatores de ordem institucional que fazem as organizações caminharem no mesmo sentido. Associado a este entendimento está o reconhecimento de um suposto processo de homogeneização não apenas entre as estruturas e condutas das empresas, mas também de organizações situadas em outros campos, tais como governos, partidos políticos e movimentos sociais Jarvis, 2014; Forni \& Leite, 2006; Ramanath, 2009; Radaelli, 2000; Arvidson \& Lyon, 2014).

Na versão mais difundida dessa teoria, Dimaggio \& Powell (1983) identificam três tipos de isomorfismo. O primeiro, denominado "coercitivo", deriva das pressões (coerção, persuasão) exercidas por outras organizações que determinam estruturas e condutas. Em alguns casos, esta pressão advém diretamente de outra organização do mesmo setor ou campo. Em outros casos, ela pode ser indireta, mediada pelo Estado ou por "categorias profissionais". No que tange ao Estado, destaca-se o modo como mecanismos públicos de regulação forçam as organizações a se adequarem às mesmas tecnologias. Por sua vez, as categorias profissionais podem, por exemplo, estabelecer sistemas privados de certificação que obrigam as organizações a seguir parâmetros definidos por uma elite profissional alinhada aos interesses das organizações dominantes do campo (Fouilleux \& Loconto, 2017).

De outro modo, o isomorfismo "normativo" envolve uma pressão indireta e não coercitiva - uma "atração" (Beckert, 2010) - que resulta da institucionalização de uma "cultura profissional" em um determinado campo. Este processo é catalisado pelas lutas entre os membros de uma "profissão" para legitimar as bases cognitivas e valorativas dos seus conhecimentos. Embora não exclusivos, os principais mecanismos de legitimação seriam a educação formal nas universidades e centros de treinamento e a formação de redes profissionais. Estudos sobre a trajetória similar de administradores de empresas e gestores públicos demonstram a força destes mecanismos (Ellersgaard et al., 2013). Este tipo de isomorfismo se ancora menos em regras e sanções formais do que em convenções que se estabelecem como preceitos de ordem moral (difusão de valores). Os indivíduos e organizações as seguem em virtude da possibilidade de desaprovação social, cujo efeito pode ser mais sentido que aqueles decorrentes da coerção por instrumentos jurídicos.

Finalmente, o isomorfismo "mimético" não está relacionado com a pressão coercitiva, nem com a conformação individual às convenções coletivas. Neste caso, o foco é o mimetismo como comportamento prevalecente em contextos de incerteza. Segundo Dimaggio \& Powell (1983), quando não há parâmetros claros a serem seguidos, as informações são erráticas ou difíceis de serem interpretadas e prevalece um clima de desconfiança sobre o futuro, as organizações podem optar por imitar os "exemplos de sucesso" - que, nesta pesquisa, seria o OPAC Ecovida. O parâmetro fundamental para se tornar um "modelo a ser seguido" está associado com reconhecimento social, o que depende não apenas de eficiência econômica, mas da construção de uma imagem de organização que, inclusive por já ter vivenciado outros momentos de crise, "conhece o caminho das pedras".

A maioria dos estudos subsequentes à construção dessa tipologia empenhou-se em identificar como esses tipos de isomorfismo operam em diferentes campos. Esse esforço disseminou a agenda de pesquisa e solidificou a percepção do processo de homogeneização. No entanto, não tardou para a teoria se tornar objeto de inúmeras críticas, tais como: falta de evidências empíricas para sustentar a percepção da homogeneização; subestimação da capacidade de resistência dos atores às pressões isomórficas; foco exagerado na reprodução e persistência das instituições; e dificuldade para analisar ambientes institucionais heterogêneos (Peci, 2006; Boxenbaum \& Jonsson, 2017; Beckert, 2010).

Estudos mais recentes problematizaram a complexidade do ambiente institucional, destacando que as organizações são expostas a pressões múltiplas e, não raro, contraditórias (Greenwood et al., 2011). Como destaca Beckert (2010, p. 151), "ao invés de ver a evolução institucional como a convergência para um modelo, [esses estudos] enfocaram a contínua, e novamente emergente, divergência institucional". Com isso, uma 
das primeiras mudanças foi o reconhecimento de que as supostas causas da homogeneização podem, ao contrário, constituírem fatores de diferenciação institucional. Neste sentido, Beckert (2010) sugere que a coerção exercida por um ator externo pode ser utilizada para forçar a adoção de designs organizacionais diferentes do modelo original. 0 autor cita as imposições impetradas pelos Estados colonialistas, as quais forçam as colônias a manter estruturas institucionais diferentes das metrópoles com vistas a facilitar a espoliação de recursos.

Com relação ao isomorfismo normativo, cuja força motriz é a "atração" que determinados modelos considerados mais legítimos exercem sobre as organizações, Beckert (2010) questiona até que ponto os centros de educação e as redes profissionais ainda reproduzem a lógica da "solução única". Para o autor, já se generalizou dentre os think tanks internacionais o entendimento de que cada contexto requer modelos específicos e que "é imprudente importar uma instituição de outro ambiente institucional se ela não estiver conectada ao arranjo institucional original" (Beckert, 2010, p. 10). Sendo assim, a convenção prevalecente exerceria uma atração em favor da diversidade. Finalmente, com relação ao mimetismo, o autor afirma que a imitação depende não apenas do reconhecimento do sucesso da organização imitada em lidar com as incertezas, mas da adequação de suas práticas a identidades culturais e valores localmente legitimados. Neste caso, o autor não aponta a imitação como fonte de diversidade, mas destaca os limites do processo.

Dessa discussão deriva uma questão relevante sobre os fatores que produzem isomorfismo. A maioria das análises toma como pressuposto que a difusão de ideias, políticas, valores, regras, padrões etc. implica em crescente homogeneidade. No entanto, “em contraste com o pressuposto teórico de que difusão é igual a isomorfismo, os resultados empíricos revelaram muitos casos de dissimilaridade organizacional, mesmo em campos organizacionais maduros." (Boxenbaum \& Jonsson, 2017). Ratificando o argumento de Beckert (2010), Boxenbaum \& Battilana (2005), demonstram que a difusão pode ser fonte de inovação e produzir maior heterogeneidade no campo organizacional. A explicação está associada ao fato de que o processo de tradução das normas, políticas ou padrões que estão sendo "difundidos" geralmente incorre em uma reinterpretação contextualizada e na "traição" do "modelo original". Na mesma perspectiva, Hassenteufel (2008) defende que a "cópia" geralmente é parcial e incompleta e o que predomina são modelos híbridos e, portanto, maior diversidade.

A preocupação com a diferenciação institucional estimulou pesquisas sobre processos de dissociação (decoupling). Inicialmente, este conceito chamava a atenção para o fato de que as organizações adotavam apenas superficial ou discursivamente o padrão institucional dominante, ou seja, adotava-se a estrutura formal sem que isto se refletisse efetivamente nas práticas (Arvidson \& Lyon, 2014). Em virtude disso, essas organizações evitariam qualquer tipo de controle externo que pudesse revelar a dissimulação. No entanto, estudos mais recentes demonstram que as organizações também podem apostar abertamente na diferenciação, tornando-a parte da sua estratégia concorrencial no campo (Åberg, 2013; Boxenbaum \& Jonsson, 2017). Neste caso, é possível inclusive que a crítica às pressões institucionais não tenha pretensão reformista, haja vista que o sucesso da crítica (mudança institucional no campo) poderia comprometer a estratégia de diferenciação.

À medida que esta discussão ganhou espaço, duas novas questões se impuseram. A primeira diz respeito ao entendimento de que isomorfismo e dissociação são processos simultâneos e coexistentes. De acordo com Boxenbaum \& Jonsson (2017), enquanto os estudos empíricos se empenham em demonstrar qual destes processos prevalece, poucos avanços têm sido feitos para entender as interações entre eles, "incluindo as condições sob as quais eles ocorrem e os efeitos institucionais que eles produzem". A segunda questão diz respeito aos fatores que promovem a dissociação - subentendido aqui que as causas do isomorfismo já eram uma questão central. A revisão da literatura apresentada pelos autores aponta para as variáveis que têm recebido maior atenção: vantagens concorrenciais da diferenciação, dinâmicas de poder internas às organizações; preocupação com a imagem e a reputação da organização; efeitos não intencionais de práticas discursivamente 
legitimadas; e pressões exercidas por redes e atores externos ao campo (Boxenbaum \& Jonsson, 2017). Nas próximas seções, depois de apresentar as estruturas e condutas dos OPACs, discutiremos os fatores de diferenciação institucional identificados em nossa pesquisa.

\section{A institucionalização dos OPACs no estado do Rio Grande do Sul}

Do ponto de vista regulatório, existem três marcos principais na institucionalização dos orgânicos no Brasil: a Lei n. 10.831/2003, o Decreto n. 6.323/2007 que a regulamenta e a Instrução Normativa 19/2009. A análise do conteúdo destes instrumentos normativos revela três aspectos principais. Primeiro, a generalidade da lei, a qual não fez mais do que definir de maneira bastante abrangente o que é um sistema de produção orgânico, deixando margem para múltiplas interpretações e, na prática, tendo quase nenhum efeito do ponto de vista da estruturação do mercado (Niederle, 2014). Segundo, a longa duração entre a promulgação da lei e a regulamentação dos processos de certificação, do que é possível inferir a existência de desentendimentos que não permitiram um processo mais célere. Terceiro, que mesmo a IN 19/2009, instrumento mais detalhado de regulamentação dos sistemas de garantia, exige uma série de estruturas formais dos OPACs, mas, como se confirmará a seguir, é flexível com relação às condutas ou procedimentos de certificação.

Para compreender o desenho deste arranjo institucional, é necessário olhar rapidamente para a trajetória de lutas sociais das organizações que confluíram para um movimento em prol do que atualmente se conhece como "agroecologia" (Figura 1). Originadas dos grupos de "agricultura alternativa" do final dos anos 1970, no começo da década de 1990 essas organizações passaram a enfrentar a pressão institucional do governo federal para a regulamentação da produção orgânica. Esta pressão respondia, por sua vez, às exigências da inserção brasileira na Organização Mundial do Comércio e ao interesse de empresas privadas na venda de alimentos orgânicos nos mercados internacionais, para o que era exigida a certificação auditada. No entanto, desde a perspectiva do movimento agroecológico, a certificação se imporia como uma barreira para os agricultores familiares e deturparia o significado da agroecologia, então compreendida como um conjunto de práticas sociais e de relações sociedade-natureza que não se limita ao cultivo de alimentos sem agrotóxicos ou outros insumos sintéticos. Com efeito, a primeira reação do movimento agroecológico foi a de resistir à pressão do campo institucional pela certificação (Petersen et al., 2013; Rosset \& Altieri, 1997).

Em meados dos anos 1990, quando a certificação já se mostrava um caminho sem retorno, as organizações agroecológicas começaram a se articular para construir modelos alternativos de controle. Em 1996, surgiram as primeiras discussões que levaram, dois anos depois, à criação da Rede Ecovida de Certificação Participativa, a qual passou a articular organizações locais que, até então, estavam desarticuladas e dispersas em diferentes territórios do sul do país. A partir do sucesso desta experiência emergiram os principais subsídios utilizados pelos representantes do movimento agroecológico — agora já articulados em rede na Articulação Nacional de Agroecologia - para persuadir o governo a reconhecer sistemas alternativos de certificação. Esta demanda foi acolhida em virtude da capacidade de mobilização do movimento agroecológico, mas também da concepção compartilhada no campo organizacional de que cada tipo de certificação ocuparia espaços específicos de mercado, sem comprometer os interesses dos diferentes atores envolvidos. Enquanto a auditoria estaria voltada às exigências do grande varejo e da exportação, a certificação participativa seria direcionada à demanda dos circuitos curtos e localizados. ${ }^{4}$

Outro fator fundamental para o reconhecimento da certificação participativa foi o ingresso de uma nova coalizão política no Governo Federal em 2003. A eleição do presidente Lula criou uma janela de oportunidade para os movimentos agroecológicos não apenas resistir às pressões regulamentares, mas para adentrar nos espaços de produção

${ }^{4}$ Com o passar do tempo esta concepção se mostrou parcialmente equivocada, haja vista a crescente coexistência da certificação por auditoria e participativa nos diferentes mercados (Niederle, 2014). 
das instituições, com destaque, neste caso, para a Comissão Nacional de Produção Orgânica - CNPOrg, estabelecida em 2004 para aprovar as normas e procedimentos da produção orgânica. A proliferação destes espaços de participação social facilitou a articulação entre as organizações do movimento agroecológico e, a partir disso, contribuiu para que elas se tornassem atores "incumbentes" (Fligstein \& McAdam, 2012), ou seja, de organizações locais e periféricas reagindo às pressões do campo, elas se tornaram parte de um movimento que passou a participar ativamente da produção das normas e regras.

\begin{tabular}{|c|c|c|c|}
\hline $\begin{array}{l} \\
\vdots \\
1989 \\
\vdots \text {-Certificação participativa } \\
\vdots \text { Coolmeia } \\
\vdots 1986 \\
\vdots \text { - Criação do CETAP } \\
\vdots 1985 \\
\vdots \text { - Criação do Centro } \\
\text { Ecológico }\end{array}$ & $\begin{array}{l}1998 \\
\text { - Criação da Rede Ecovida de } \\
\text { - Certificação Participativa } \\
1997 \\
\text { - Formação de grupos de } \\
\text { agricultores ecológicos em } \\
\text { Porto Alegre } \\
\text { - Criação da ANAMA } \\
1996 \\
\text { - Inicio discussőes para } \\
\text { - criação da Rede Ecovida }\end{array}$ & $\begin{array}{l}2009 \\
\text {-Fórum Brasileiro e Latinoamericano de } \\
\text { SPGs } \\
2006 \\
\text { - Fundação da COMAFITT } \\
\text { - Fechamento da Coolmeia } \\
2005 \\
\text { - Fundação da Cooperativa Econativa } \\
2004 \\
\text { - Certificação Arroz MST Auditoria IMO } \\
2003 \\
\text { - Fundação da COCEARGS } \\
2002 \\
\text { - Criação do Selo Ecovida }\end{array}$ & $\begin{array}{l}2017 \\
\text { - Sistema de Informação Ecovida } \\
\text {-Criação da RedeCoop } \\
2016 \\
\text {-Credenciamento OPAC RAMA } \\
2014 \\
\text { - Credenciamento OPAC COCEARGS } \\
\text { - Credenciamento OPAC Litoral Norte } \\
2012 \\
\text {-Criação da OCS COCEARGS } \\
2011 \\
\text {-Criação da OCS RAMA } \\
2010 \\
\text { - Credenciamento OPAC Ecovida }\end{array}$ \\
\hline 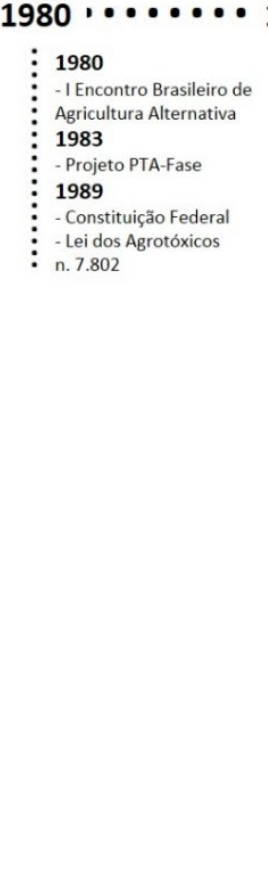 & $\begin{array}{l}90 \\
1990 \\
\text {-Criação da ASPTA } \\
1993 \\
\text { - I Grupo de Trabalho para } \\
\text { Regulamentaçăo dos } \\
\text { Orgânicos } \\
1999 \\
\text { - Instrução Normativa IN } 07 \\
\text { MAPA de regulaçăo dos } \\
\text { Orgânicos } \\
\text { - Seminário de Agroecologia } \\
\text { de Porto Alegre } \\
\text { - Criação do Ministério do } \\
\text { Desenvolvimento Agrário }\end{array}$ & $\begin{array}{l}2000 \\
\text { Articulação Nacional de Agroecologia } \\
2002 \\
\text { - Grupo de Agricultura Orgânica MAPA } \\
2003 \\
\text { - Lei dos Orgânicos n. 10.831 } \\
\text { - Criação do PAA Alimentos } \\
\text { - I Congresso Brasileiro de Agroecologia } \\
2004 \\
\text { - Criação da PNATER } \\
\text {-Criação da CNPOrg e CPORgs } \\
2005 \\
\text { - PRONAF Agroecologia } \\
2007 \\
\text { - Decreto n. } 6.323 \text { (Regulamenta Lei n. } \\
\text { 10.831) } \\
2008 \\
\text { - IN MAPA n. } 64 \text { (Regulamenta Lei n. } \\
\text { 10.831) - Regulamento Técnico } \\
\text { Orgânicos } \\
2009 \\
\text { - Alteração do PNAE (30\% AF) } \\
\text { - Decreto n. } 6.913 \text { (Registro de produtos } \\
\text { fitossanitários para agricultura orgânica) } \\
\text { - IN MAPA/MMA n. 17 (Extrativismo } \\
\text { sustentável orgânico) } \\
\text { - IN MAPA/MS n. 18 (Processamento de } \\
\text { produtos orgânicos) } \\
\text { - IN n. 19 (Regulamenta funcionamento } \\
\text { dos Mecanismos de Controle) } \\
\text { - IN MAPA n. } 50 \text { (Selo único oficial do } \\
\text { Sistema Brasileiro de Avaliação da } \\
\text { Conformidade Orgânica) }\end{array}$ & $\begin{array}{l}10 \\
2010 \\
\text { - Inicio da execução do Decreto 6.323 OPACS } \\
\text { - Lei de ATER e PRONATER } \\
2011 \\
\text { - IN MAPA n. 46- Regulamento Técnico } \\
\text { Orgânicos (Revoga IN MAPA n. 64/2008) } \\
\text {-Cadastro Nacional de Produtores Orgânicos } \\
2012 \\
\text { - Política Nacional de Agroecologia e } \\
\text { Produção Orgânica (PNAPO) } \\
2013 \\
\text {-Plano Nacional de Agroecologia e Produção } \\
\text { Orgânica (PLANAPO) } \\
2014 \\
\text { - IN MAPA n. 17-Regulamento Técnico } \\
\text { Orgânicos } \\
\text { - IN MAPA n. 18 - Selo “Orgânico Brasil” } \\
\text { (Revoga IN MAPA n. 50/2009) } \\
2016 \\
\text { - Coordenação de Orgânicos em novo setor } \\
\text { no MAPA } \\
\text { - Início da desestruturação das politicas de } \\
\text { ATER e outras politicas para a AF }\end{array}$ \\
\hline
\end{tabular}

Figura 1. Trajetória de reconhecimento e institucionalização da certificação participativa. Fonte: elaborado pelos autores.

A partir desse momento, no interior do movimento agroecológico e do próprio campo organizacional prevaleceu o entendimento de que, quanto menor o nível de constrangimento institucional, maior seria a capacidade de cada organização adequar os procedimentos à sua realidade e, em virtude disso, maior a possibilidade de avançar em processos graduais e inclusivos de "transição agroecológica". Em virtude disso, o Brasil produziu um arranjo regulatório ambíguo, no qual os dispositivos procuram estabelecer parâmetros adaptáveis aos contextos locais. Este arranjo obrigou os OPACs a, por exemplo, constituírem uma organização formal, redigirem um manual de procedimentos, criarem uma comissão de verificação e definirem roteiros de visita para execução do controle, mas não foram definidos parâmetros precisos para determinar como isto deveria ser feito. 


\subsection{Associação Ecovida de Certificação Participativa}

A partir dos parâmetros da IN 19/2009, a Rede Ecovida registrou, em 2010, a Associação Ecovida de Certificação Participativa. Esta se tornou o órgão formal responsável pela gestão da certificação dentro do arranjo de práticas mais abrangente que a rede organiza, tais como a capacitação de agricultores por intermédio de ONGs e a articulação de circuitos de comercialização via associações e cooperativas. Apesar da coerção institucional para criação do OPAC, no caso da Ecovida este processo foi facilitado na medida em que ela mesma serviu como o principal modelo para a construção da regulamentação. Com efeito, nos anos subsequentes o OPAC Ecovida conseguiu se expandir rapidamente ${ }^{5}$ e passou a servir direta ou indiretamente como inspiração para a criação de outros organismos.

O alicerce estrutural da Ecovida é formado por cerca de trezentos grupos que compreendem cinco mil agricultores familiares. Estes grupos estão distribuídos em 29 núcleos nos três estados do sul do Brasil. Além disso, conectados aos grupos ou diretamente aos núcleos existem 35 ONGs e uma variedade de associações e cooperativas. Em virtude deste tamanho e dispersão, a Ecovida abarca indivíduos e organizações com interesses e valores muito diversos. Nas reuniões observamos desde antigas lideranças dos movimentos de "agricultura alternativa" dos anos 1980, para os quais valores como equidade social e justiça ambiental são inquestionáveis, até neorrurais que ingressaram no OPAC apenas em busca de uma certificação mais barata para reduzir seus custos ou para acessar os mercados organizados pela Rede Ecovida (principalmente as feiras e os programas de compras públicas). Essa heterogeneidade faz a Ecovida adotar um arranjo institucional flexível, permitindo que os núcleos definam regras e procedimentos próprios ${ }^{6}$ de acordo com suas condições locais.

No que tange especificamente ao processo de certificação, a estrutura central é a comissão de verificação/avaliação. No caso da Ecovida, existe uma comissão para cada núcleo, a qual é composta por dois representantes por grupo. Para a realização da visita cruzada entre os grupos, esta comissão escolhe um comitê de verificação composto por, no mínimo, três integrantes da comissão, sendo que as regras de escolha podem variar entre os núcleos, desde que dois membros sejam externos ao grupo verificado. Este comitê realiza o controle e redige um relatório a ser apreciado pela comissão. No caso de conformidade, esta encaminha os documentos para os técnicos do escritório geral do OPAC, os quais credenciam os agricultores certificados junto ao Mapa. Se forem identificadas inconformidades, o relatório sugere ao agricultor alterações nas práticas produtivas - 0 que é proibido no caso da certificação por auditoria. Caso o agricultor discorde da avaliação, ele pode recorrer ao Conselho de Recursos que, no OPAC Ecovida, é formado pelos próprios membros da comissão de verificação, exceto aqueles que participaram da visita cruzada (Figura 2).

A produção das normas e procedimentos do OPAC Ecovida se concentra na assembleia geral, a qual se confunde com a plenária geral de núcleos (instância da Rede Ecovida), em que se reúnem os representantes das comissões de verificação (que, em geral, são os próprios coordenadores dos núcleos da Rede Ecovida). Nota-se, portanto, que a estrutura deste OPAC se confunde com aquela da Rede, o que cria confusão inclusive para as próprias lideranças da organização, muitas das quais mencionaram nomenclaturas distintas nas entrevistas para caracterizar órgãos que desconhecem como eles realmente se estruturam. Exemplo disso é o fato de que por mais que o OPAC tenha uma direção formalmente constituída, haja vista que é registrada como uma associação, poucos entrevistados tinham ciência da existência desta estrutura e de quem são seus membros.

\footnotetext{
${ }^{5}$ Esta expansão foi potencializada pelas políticas públicas de aquisição de alimentos, tais como o Programa de Aquisição de Alimentos (PAA) e o Programa Nacional de Alimentação Escolar (PNAE).

${ }^{6}$ À título de exemplo, com referência à "produção paralela" (coexistência de produção orgânica e convencional no mesmo estabelecimento rural), enquanto alguns núcleos criaram regras de transição exigindo evidências do esforço do agricultor para substituir o convencional pela produção orgânica dentro do período regulamentar de cinco anos, outros não aceitam esta prática em nenhuma circunstância.
} 


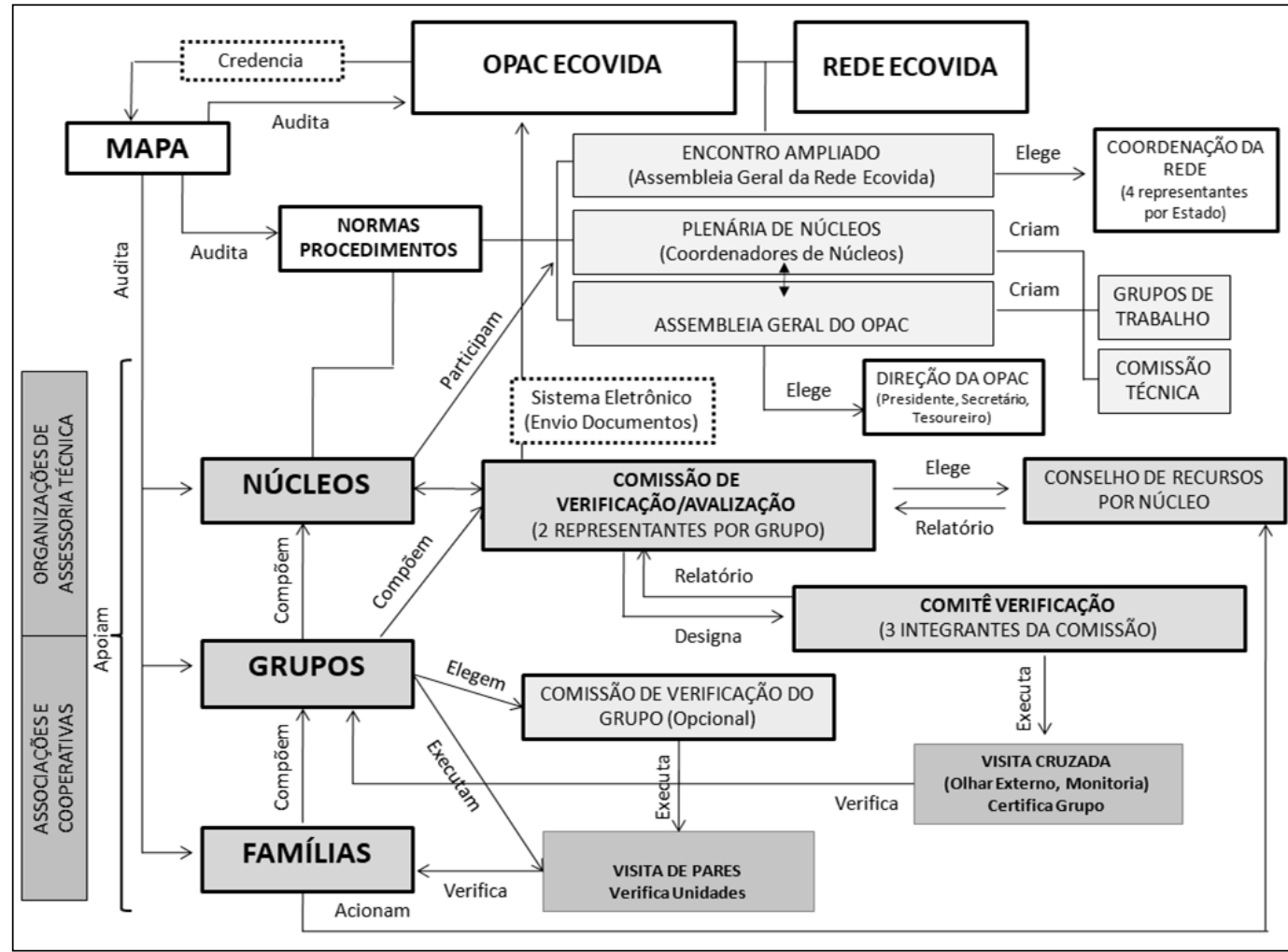

Figura 2. Arranjo organizacional do OPAC Ecovida. Fonte: elaborado pelos autores.

A maioria das estruturas organizacionais é assessorada por profissionais técnicos das ONGs que compõem a Rede Ecovida. Estes podem ser identificados na "categoria profissional" sublinhada por Dimaggio \& Powell (1983). A origem destes técnicos é relativamente similar. Os mais antigos são oriundos de movimentos sociais agrários e ecologistas ou de movimentos estudantis, sobretudo dos Grupos de Agricultura Ecológica criados nos anos 1990 nas faculdades de agronomia. Os mais novos já são filhos de agricultores membros da Rede. Em virtude desta origem comum, eles compartilham uma cultura similar, mas, assim como destaca Beckert (2010), esta é marcada pela compreensão de que as soluções adequadas são variáveis a cada agricultor, grupo ou núcleo. Com isso, se evitaria uma pressão isomórfica interna à própria Rede, ou seja, a cópia dos modos de ação entre os diferentes grupos ou núcleos. Não obstante, o que se percebeu é que os técnicos assumem um papel central na estruturação de grupos e núcleos novos e, neste caso, exercem diferentes níveis de pressão normativa para que estes se adequem ao modo de funcionamento do OPAC. Em alguns núcleos, os técnicos, inclusive, assumem a coordenação e representação dele. De outro modo, nos grupos e núcleos mais estruturados, em que a cultura organizacional já está consolidada, eles procuram transferir essas funções para os agricultores.

\subsection{Coceargs}

Assim como no caso da Ecovida, o OPAC Coceargs está diretamente vinculado a uma organização mais ampla, a Cooperativa Central dos Assentamentos do Rio Grande do Sul (Coceargs), a qual articula as estratégias de comercialização de cinco cooperativas criadas pelo Movimento dos Trabalhadores Rurais Sem Terra (MST) no Rio Grande do Sul. Formalizado em 2014, este OPAC abarca 120 famílias distribuídas em 18 grupos, os quais, por sua vez, estão ligados às cooperativas. Como não existem núcleos tal como na Ecovida, os processos de certificação se concentram em uma única comissão de avaliação (Comissão Estadual OPAC). Formada por representantes e técnicos da Coceargs e das cooperativas locais, esta comissão produz as regras e procedimentos de certificação e, ao mesmo tempo, 
coordena e executa as visitas em todos os grupos, geralmente com o apoio de técnicos locais que assessoram os assentados (Figura 3).

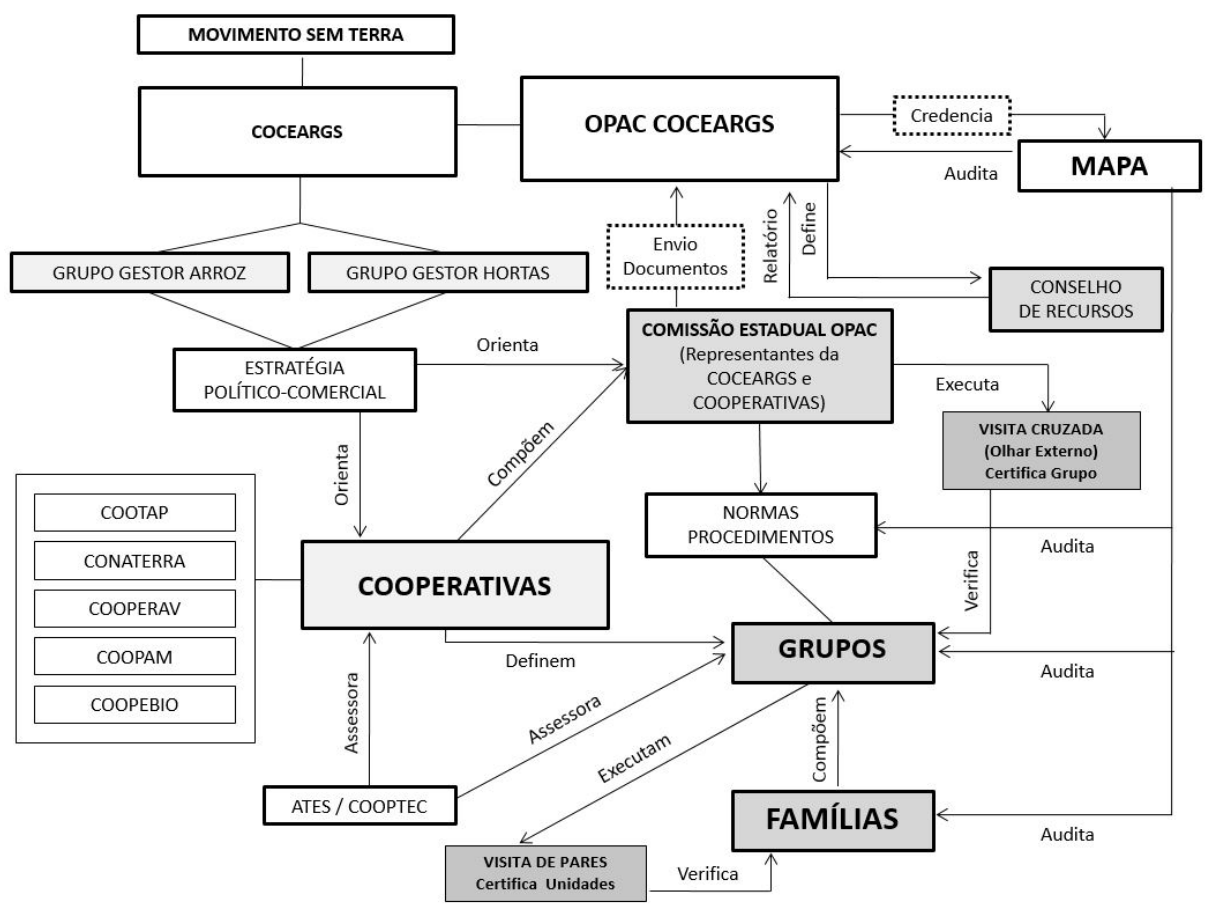

Figura 3. Arranjo organizacional do OPAC Coceargs. Fonte: elaborado pelos autores.

Inicialmente, a construção do OPAC Coceargs contou com a consultoria de um técnico do OPAC Ecovida. No entanto, conforme este nos informou em entrevista, logo ficou evidente que seria necessário produzir um modelo de certificação distinto. Além de um público específico e menos heterogêneo, a principal diferença em relação ao formato da Ecovida era a centralidade da Coceargs em todo o processo. Para o MST, a construção da certificação respondia, antes de tudo, aos interesses comerciais das suas cooperativas. Neste sentido, cabe notar que a produção de arroz orgânico (principal produto comercializado pelo MST no RS) sempre foi certificado por auditoria de terceira parte. Ainda hoje 370 famílias são certificadas por este sistema. No entanto, a maioria destas famílias nunca esteve realmente envolvida no processo. Dentro de cada grupo, somente alguns assentados se ocupam da produção, estabelecendo acordos de distribuição dos lucros entre as famílias que possuem a posse das áreas. Este sistema fez com que o próprio processo de certificação por auditoria não verificasse cada família separadamente, haja vista que há uma única área de produção.

A estruturação do OPAC Coceargs revela uma dependência parcial de caminho com relação a este sistema de auditoria, com a diferença que, ao invés de uma empresa externa, a comissão estadual passou a executar um processo de "quase auditoria". Em virtude deste nível de centralização dos processos de decisão e execução, em 2018 uma auditoria do Mapa demandou reformulações no OPAC com vistas a ampliar a participação dos agricultores. Colocado em prática a partir de 2019, este processo foi acelerado por uma mudança em outro campo organizacional. Em 2017, como decorrência da extinção do programa público de Assistência Técnica e Social aos Assentamentos (Ates) e, portanto, a crise da Cooptec (cooperativa de técnicos ligada ao MST que acessava recursos deste programa), o OPAC Coceargs foi obrigado a aumentar o nível de engajamento dos assentados e grupos. Até o momento, esta reestruturação tem sido mais eficaz dentre os grupos de produção de hortaliças, os quais possuem formatos mais participativos de organização, consequência do fato de que eles não estavam integrados na certificação por auditoria, mas em uma OCS. 
Em 2012, antes de registrar o OPAC, a Coceargs obteve registro de uma OCS para viabilizar a venda direta dos assentados nas feiras livres. Desde então, constituiu três OCSs totalizando 16 grupos que abarcam 53 famílias. Como a estrutura e funcionamento de uma OCS são mais próximos àqueles da certificação participativa, muitas organizações compreendem-na como um passo inicial até o registro do OPAC. O mesmo tipo de estratégia marcou, por exemplo, a origem do OPAC Rama (Associação dos Produtores da Rede Agroecológica Metropolitana), cuja OCS foi registrada em 2011 e o OPAC em 2016. Com efeito, muitos agricultores sequer identificam as diferenças entre estes mecanismos, o que cria dificuldades na "migração" de um para outro, haja vista o maior nível de controle e burocracia da certificação participativa. Este também é um fator que limita uma tentativa de cópia do "modelo Ecovida" considerando que esta organização não teve uma OCS na sua origem.

\subsection{Rama}

O OPAC Rama congrega 45 famílias da região metropolitana de Porto Alegre. Diferentemente dos dois casos anteriores, mas similarmente ao OPAC Litoral Norte (ver infra), neste caso não existe uma organização mais ampla à qual as decisões do OPAC estão submetidas. Além disso, o foco das ações é a certificação e, associada a isto, a capacitação dos produtores, mas não a articulação de circuitos de comercialização, de modo que não existem cooperativas ou associações diretamente vinculadas ao OPAC. Outra particularidade em relação às demais experiências é a presença de consumidores nas reuniões e no próprio processo de certificação, o que é facilitado pela proximidade com um centro urbano e, também, pela longa trajetória do movimento ecológico na cidade de Porto Alegre. Neste sentido, cabe destacar a experiência da Cooperativa Ecológica Coolmeia (Figura 1, supra) que, em 1989, articulou a primeira feira de produtos ecológicos no RS, bem como um sistema próprio de certificação participativa. Embora esta cooperativa tenha sido extinta em 2004, a feira se manteve, assim como a memória institucional da organização, da qual participaram vários agricultores atualmente associados ao OPAC Rama.

Os aspectos organizacionais que mais chamam atenção no OPAC Rama são o nível de descentralização das decisões acerca de normas e procedimentos e, principalmente, a estrutura de verificação da conformidade. Com relação a este último aspecto, a principal singularidade é o fato de que os grupos não são fixos como ocorre nos demais OPAC (Figura 4). Anualmente, um sorteio realizado na plenária geral define a participação de cada família em um dos oito grupos do OPAC. Em seguida, cada grupo indica um representante para compor a comissão de avaliação, a qual, por sua vez, escolhe dois agricultores e um "colaborador" (técnico ou consumidor) para compor a comissão de visitação responsável por executar anualmente a "visita de conformidade" em cada propriedade. Neste tipo de organização, diferentemente das demais analisadas, não há distinção entre a "visita de pares" (interna ao grupo) e a "visita cruzada" (entre representantes de diferentes grupos).

Um aspecto similar, contudo, é a centralidade dos técnicos, mas com uma diferença importante no que diz respeito ao fato de que, neste caso (assim como no OPAC Litoral Norte) é a Emater que está à frente do processo. A articulação dos agricultores foi impulsionada, no final dos anos 1990, pela ação de técnicos da Emater em parceria com atores de outras organizações, como a Prefeitura Municipal de Porto Alegre e universidades, e com assessoria do Centro Ecológico - uma das principais ONGs da Rede Ecovida (Cruz et al., 2016). Quando da estruturação da OCS e do OPAC Rama, estes técnicos assumiram posição de destaque no desenho da organização e na coordenação das discussões para redação das normas e procedimentos. Atualmente eles estão presentes em todas as etapas do processo e o OPAC Rama é o único que prevê em seu regimento a obrigatoriedade da participação de um "colaborador" na comissão de visitação, o qual, geralmente, é um técnico.

Inicialmente, esta relevância dos técnicos nos sugeria a possibilidade de um processo pouco participativo. No entanto, a observação dos espaços de discussão e das práticas de certificação mostrou justamente o inverso. Comparativamente às demais, foi neste OPAC 
que identificamos a participação mais ativa do conjunto dos atores em todas as etapas da certificação. Isto se deve, primeiro, à estrutura descentralizada de decisões, as quais ocorrem em Plenárias e Assembleias com a participação de todas as famílias (ao invés de representantes como ocorre na Ecovida e Coceargs). Segundo, à cultura profissional dos técnicos que, mesmo não atuando em ONGs e movimentos sociais, compartilham valores e ideais do movimento agroecológico. Terceiro, à proximidade espacial e ao perfil dos agricultores, principalmente ao fato da maioria ter formação universitária, o que reduz a assimetria de conhecimentos e de capacidade comunicacional em relação aos técnicos.

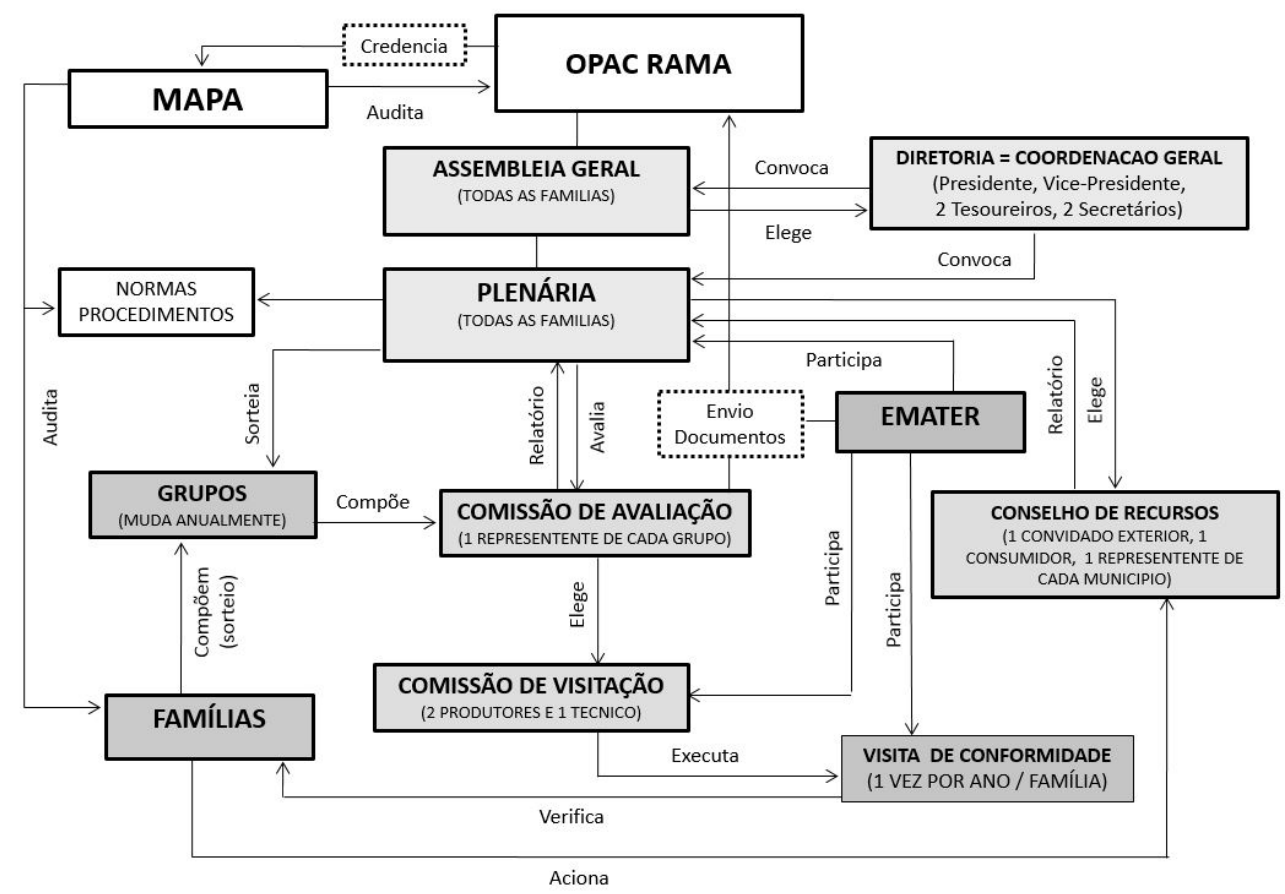

Figura 4. Arranjo organizacional do OPAC Rama. Fonte: elaborado pelos autores.

\subsection{Litoral Norte}

O OPAC Litoral Norte foi registrado em 2014 e, atualmente, reúne 70 famílias distribuídas em sete grupos. Este OPAC atua em uma região geográfica que se sobrepõe parcialmente ao Núcleo Litoral Solidário da Rede Ecovida. Um dos motivos que incitaram sua criação foi justamente o descontentamento de alguns atores com as exigências da Ecovida. Este fato criou, inclusive, uma resistência interna à ideia de cópia do "modelo Ecovida", o que foi verificado em várias intervenções nas plenárias do OPAC que demarcaram as diferenças entre ambos organismos de certificação participativa.

O OPAC Litoral Norte opera com Assembleias bimestrais que reúnem todas as famílias, uma opção que tem sido desafiada pelo crescimento das demandas de ingresso de novos membros. Segundo entrevistados, isto poderá levar à criação de mecanismos de representação que potencializem o aprofundamento das discussões. A observação destas assembleias revelou que este espaço é utilizado principalmente para difusão de informações e apreciação dos relatórios emitidos pela comissão de verificação, órgão responsável pela organização das visitas cruzadas (Figura 5). A configuração deste espaço dificulta a produção de decisões importantes, como a aprovação da proposta de novo regimento interno em discussão há cerca de dois anos. Este fato também demonstra que a transferência das decisões para assembleias gerais não é garantia de ampla participação social. Apesar da presença de um grande número de pessoas, as intervenções que efetivamente colocam em pauta as regras e procedimentos da certificação se concentram em um número limitado de atores, sobretudo nos membros da diretoria e técnicos que a assessoram. 
Também contribui para limitar a participação o fato de que a maioria dos agricultores ingressou recentemente no OPAC, muitos dos quais apenas com o interesse utilitário de acessar o selo para comercializar seus produtos. Com efeito, membros da diretoria do OPAC afirmaram em entrevistas que um dos esforços mais importantes tem sido fazer os novos membros compreenderem os princípios e valores da agroecologia, o que abarca, dentre outras coisas, o engajamento na construção coletiva da organização. Para tanto, assim como ocorre em alguns núcleos da Rede Ecovida, desde 2018 o OPAC passou a exigir que, para obter o registro, os novos associados participem de um curso de formação sobre agroecologia, o qual geralmente é coordenado pelos técnicos da Emater ligados ao OPAC. Outras iniciativas com vistas a incrementar a participação social têm se dado a partir de parcerias com duas cooperativas que possuem vínculos estreitos com o OPAC, a saber: Comafit e Coopviva. Embora estas não estejam diretamente associadas ao processo de certificação, elas têm incentivado seus membros a ingressar no OPAC com vistas a aumentar a capacidade de oferta de produtos orgânicos. Atualmente, a maioria das reuniões do OPAC ocorre na sede destas cooperativas, sendo que uma delas também abriga a documentação e o escritório do OPAC.

Assim como no caso da Rama, no OPAC Litoral Norte também foram os técnicos da Emater que estiveram à frente da sua formação, articulando os produtores, colaborando para o desenho organizacional e institucional da certificação, viabilizando os procedimentos de verificação com infraestrutura e, inclusive, ocupando o papel de secretaria do OPAC, se responsabilizando pela organização e registro dos documentos da certificação. No entanto, à diferença do que ocorreu na região metropolitana de Porto Alegre, estes técnicos têm uma aproximação muito mais recente com o movimento agroecológico. Em virtude disso, também se revela uma cultura profissional diferenciada não apenas daquela das ONGs e do MST, mas também dos técnicos da mesma organização que atuam na região metropolitana de Porto Alegre com a Rama. Em certo sentido, no caso do Litoral Norte os próprios técnicos ainda estão passando por um processo gradual de transição em direção à agroecologia.

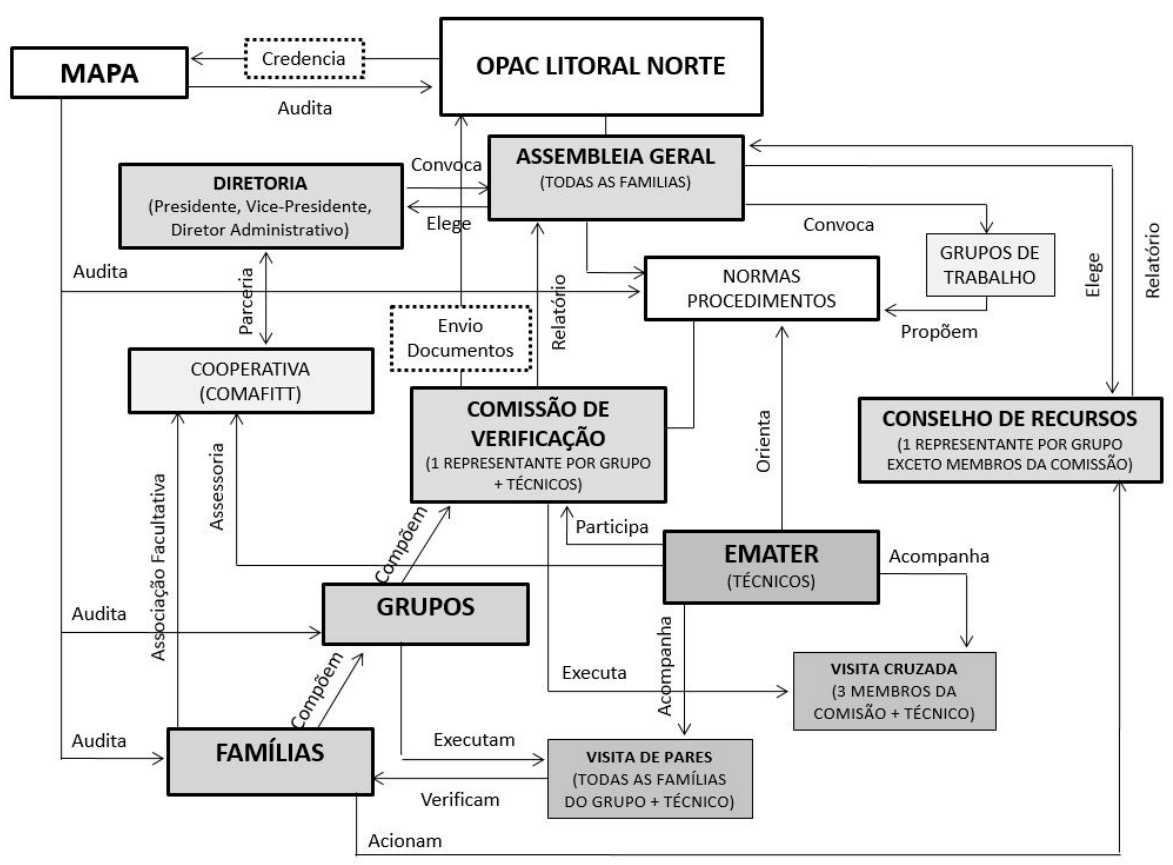

Figura 5. Arranjo organizacional do OPAC Litoral Norte. Fonte: elaborado pelos autores.

\subsection{Alguns elementos de comparação}

O Quadro 1 sintetiza as principais características dos OPACs analisados, revelando que a diversidade não está apenas na estrutura, mas também nas condutas dessas organizações. Em primeiro lugar, destaca-se o papel diferenciado dos grupos. Por exigência 
legal, sempre há grupos envolvidos na certificação, mas há diferenças no modo como eles são constituídos e nas funções que efetivamente exercem. No OPAC Coceargs, por exemplo, eles são fixos e refletem, antes de tudo, a estrutura organizacional e os interesses comerciais da cooperativa. De outro modo, na Rama os grupos se alteram todos os anos e tem a certificação como atribuição exclusiva. Na Ecovida os grupos são fixos, mas há diferenças internas nas formas de organização. Com efeito, enquanto alguns são desenhados apenas para operar os processos de certificação, outros também se organizam para viabilizar a comercialização.

A maior ou menor centralidade dos agricultores e grupos na certificação está associada com a atuação dos técnicos que assessoram os OPACs. Como vimos acima, em todas as organizações analisadas, eles são atores relevantes, mas isto não significa que atuem do mesmo modo. Na Ecovida há uma diferenciação importante na assessoria dos grupos novos ou antigos. O que é mais marcante, todavia, é que nos dois OPAC assessorados pela Emater, a atuação deste órgão se mostra bastante distinta e isto se deve, principalmente, à compreensão que os técnicos possuem sobre o quanto os membros do OPAC dominam os processos de certificação. Enquanto na Rama os técnicos assumem um papel predominantemente orientador, ainda que participando ativamente, no Litoral Norte a ação é mais diretiva, coordenando os demais atores nas reuniões e mesmo durante as visitas de certificação.

Outra diferença diz respeito à execução da etapa mais relevante do processo de certificação participativa, a "visita cruzada", ou como denomina a maioria dos atores, o "olhar externo" (termo herdado do "modelo Ecovida"). Embora a legislação estabeleça que a responsabilidade deste procedimento seja da Comissão de Avaliação, em cada OPAC há formatos e condutas específicas. Na Ecovida, esta comissão é formada por representantes dos grupos do mesmo núcleo e, para a execução das visitas, são escolhidos três membros. $\mathrm{Na}$ Coceargs existe uma comissão estadual formada por representantes da cooperativa e dos grupos, mas o trabalho de avaliação da conformidade geralmente é executado pelo corpo técnico da Coceargs. No Litoral Norte, os responsáveis pela visita são escolhidos pela diretoria do OPAC em comum acordo com os técnicos da Emater. Finalmente, no caso da Rama, a comissão é substituída pela visita cruzada entre os grupos (um grupo visita o outro), o que é facilitado pela sua proximidade geográfica.

Os processos decisórios também são diferenciados. No caso da Ecovida, prevalece um modelo de democracia representativa, em que as decisões passam por representantes escolhidos pelos grupos. Em grande medida, isso decorre do tamanho e da dispersão da rede. As decisões operacionais mais relevantes são tomadas na assembleia do OPAC, que geralmente se confunde com a plenária dos núcleos. No entanto, questões mais amplas de natureza política são remetidas às instâncias de coordenação da Rede Ecovida, incluindo um encontro ampliado que a cada três anos reúne cerca de dois mil membros. De outro modo, os casos da Rama e do Litoral Norte, cujos OPACs são relativamente pequenos e territorialmente concentrados, revelam algo mais similar a um modelo de democracia direta, em que todos os membros são chamados a decidir sobre as normas em Assembleias. Como nestes casos não há dependência hierárquica a outra organização, todas as decisões se passam no interior dos OPACs. Há ainda o caso específico da Coceargs, cuja centralização das decisões na comissão estadual repercute o modelo de organização hierárquica adotado pelo MST. Com efeito, muitas decisões que envolvem a certificação são tomadas em instâncias políticas que não estão previstas na estrutura formal do OPAC.

Finalmente, é importante notar que cada OPAC é expressão de uma organização conformada por atores e valores específicos, o que reflete diferentes concepções acerca da agroecologia e da própria certificação participativa. Em virtude do seu vínculo com o MST, o OPAC Coceargs é aquele que em que a agroecologia foi mais fortemente adotada como elemento-chave de uma narrativa política contra o agronegócio. Nos demais OPACs esta associação é menos recorrente, quando não objeto de desentendimentos. No Litoral Norte, as discussões do OPAC se concentram quase exclusivamente nos aspectos técnicos da produção orgânica, evitando adentrar em conflitos de natureza política. No caso da Ecovida, estes conflitos estão sempre presentes, mas há processos constantes de mediação para que 
eles não coloquem em risco a própria organização como coalizão política. Exemplo disso foi o fato que, na abertura do encontro ampliado realizado em 2017, em pleno contexto eleitoral, a presença de lideranças e falas políticas foi substituída por um culto ecumênico. $O$ que é mais importante, todavia, é o fato de que a institucionalização da certificação participativa não impõe uma concepção estrita de agroecologia e, por conta disso, favorece a presença no campo de atores com interesses e valores divergentes.

Quadro 1. Síntese das principais características diferenciais dos OPACs.

\begin{tabular}{|c|c|c|c|c|}
\hline & Ecovida & Coceargs & Rama & Litoral Norte \\
\hline Ano de Registro & 2010 & 2014 & 2016 & 2014 \\
\hline $\begin{array}{l}\text { Produtores } \\
\text { certificados }\end{array}$ & 3000 & 120 & 45 & 70 \\
\hline Grupos & 300 & 29 & 8 & 7 \\
\hline $\begin{array}{l}\text { Articulação com } \\
\text { organização }\end{array}$ & $\begin{array}{l}\text { Rede Ecovida de } \\
\text { Agroecologia }\end{array}$ & Coceargs / MST & Não & Não \\
\hline $\begin{array}{c}\text { Área de } \\
\text { certificação }\end{array}$ & Região Sul do Brasil. & $\begin{array}{l}\text { Estado do Rio } \\
\text { Grande do Sul. }\end{array}$ & $\begin{array}{c}\text { Região } \\
\text { metropolitana de } \\
\text { Porto Alegre. }\end{array}$ & $\begin{array}{l}\text { Litoral Norte do Rio } \\
\text { Grande do Sul. }\end{array}$ \\
\hline Núcleos & Sim & Não & Não & Não \\
\hline Papel dos Grupos & $\begin{array}{l}\text { Certificação, } \\
\text { organização da } \\
\text { produção e } \\
\text { comercialização. } \\
\text { Grupos fixos. }\end{array}$ & $\begin{array}{l}\text { Certificação. Mas } \\
\text { no caso das hortas, } \\
\text { grupos também } \\
\text { organizam } \\
\text { comercialização. }\end{array}$ & $\begin{array}{l}\text { Apenas certificação. } \\
\text { Conformação dos } \\
\text { grupos é alterada } \\
\text { todos os anos. }\end{array}$ & $\begin{array}{c}\text { Exclusivamente } \\
\text { certificação. Grupos } \\
\text { fixos. }\end{array}$ \\
\hline $\begin{array}{l}\text { Atuação de } \\
\text { técnicos na } \\
\text { certificação }\end{array}$ & $\begin{array}{l}\text { Principalmente } \\
\text { ONGs. Central em } \\
\text { grupos novos. } \\
\text { Maior autonomia } \\
\text { para grupos mais } \\
\text { antigos. }\end{array}$ & $\begin{array}{c}\text { Principalmente } \\
\text { Cooptec. } \\
\text { Fundamental, mas } \\
\text { fim da Ates reduziu } \\
\text { protagonismo. }\end{array}$ & $\begin{array}{l}\text { Emater. Central em } \\
\text { todas as etapas, da } \\
\text { produção das } \\
\text { normas até } \\
\text { execução. Papel } \\
\text { mais orientador. }\end{array}$ & $\begin{array}{c}\text { Emater. Central em } \\
\text { todas as etapas, da } \\
\text { produção das } \\
\text { normas até } \\
\text { execução. Papel } \\
\text { mais diretivo. }\end{array}$ \\
\hline Visita Cruzada & $\begin{array}{l}\text { Comissão de } \\
\text { Verificação por } \\
\text { Núcleo escolhe } 3 \\
\text { membros para } \\
\text { compor Comitê de } \\
\text { Verificação. } \\
\text { Periodicidade varia } \\
\text { conforme núcleo. }\end{array}$ & $\begin{array}{l}\text { Trabalho ainda } \\
\text { concentrado na } \\
\text { Comissão Estadual. } \\
\text { Dinâmica de quase- } \\
\text { auditoria (em } \\
\text { reestruturação). } \\
\text { Visita cruzada a } \\
\text { cada } 4 \text { anos. }\end{array}$ & $\begin{array}{l}\text { Membros de um } \\
\text { grupo visitam } \\
\text { anualmente } \\
\text { agricultores dos } \\
\text { demais grupos. } \\
\text { Escolha por sorteio. }\end{array}$ & $\begin{array}{c}\text { Diretoria do OPAC, } \\
\text { em parceria com } \\
\text { Emater, escolhe } 3 \\
\text { membros da } \\
\text { Comissão de } \\
\text { Verificação para } \\
\text { realizar visita } \\
\text { anualmente. }\end{array}$ \\
\hline $\begin{array}{l}\text { Centro de decisão } \\
\text { sobre regras }\end{array}$ & $\begin{array}{l}\text { Assembleia do } \\
\text { OPAC. Geralmente, } \\
\text { coincide com a } \\
\text { Plenária Geral de } \\
\text { Núcleos. }\end{array}$ & $\begin{array}{l}\text { Comissão Estadual } \\
\text { com forte presença } \\
\text { dos técnicos da } \\
\text { Coceargs e } \\
\text { cooperativas. }\end{array}$ & $\begin{array}{l}\text { Plenária do OPAC } \\
\text { com participação } \\
\text { de todas as } \\
\text { famílias. }\end{array}$ & $\begin{array}{l}\text { Assembleia Geral } \\
\text { do OPAC com } \\
\text { participação de } \\
\text { todas as famílias. }\end{array}$ \\
\hline $\begin{array}{l}\text { Coordenação da } \\
\text { OPAC }\end{array}$ & $\begin{array}{l}\text { Direção do OPAC é } \\
\text { formal. } \\
\text { Coordenação da } \\
\text { Rede Ecovida é o } \\
\text { espaço de direção. }\end{array}$ & $\begin{array}{l}\text { Direção do OPAC se } \\
\text { confunde com } \\
\text { direção da } \\
\text { Coceargs. }\end{array}$ & $\begin{array}{c}\text { Direção do OPAC é } \\
\text { central. Não existe } \\
\text { outra organização } \\
\text { além do próprio } \\
\text { OPAC. }\end{array}$ & $\begin{array}{c}\text { Direção do OPAC é } \\
\text { central. Não existe } \\
\text { outra organização } \\
\text { além do próprio } \\
\text { OPAC. }\end{array}$ \\
\hline Atores e valores & $\begin{array}{c}\text { Diversificado. } \\
\text { Características e } \\
\text { nível de } \\
\text { engajamento aos } \\
\text { valores e princípios } \\
\text { da Rede variam } \\
\text { conforme Núcleo. }\end{array}$ & $\begin{array}{l}\text { Restrito a } \\
\text { assentados da } \\
\text { reforma agrária. } \\
\text { Valores e princípios } \\
\text { do MST muito } \\
\text { presentes, incluindo } \\
\text { a agroecologia. }\end{array}$ & $\begin{array}{l}\text { Predominam } \\
\text { agricultores } \\
\text { neorrurais } \\
\text { engajados em } \\
\text { movimentos da } \\
\text { agroecologia. }\end{array}$ & $\begin{array}{l}\text { Diversificado. } \\
\text { Muitos agricultores } \\
\text { sem engajamento } \\
\text { com movimentos } \\
\text { da agroecologia. }\end{array}$ \\
\hline
\end{tabular}

Fonte: pesquisa de campo, 2018. 


\section{Fatores de diversificação institucional dos OPACs}

Uma vez identificada a heterogeneidade entre os OPACs, a questão passa a ser explicar os fatores que produzem diferenciação institucional. É importante ressaltar desde já que, mesmo quando se identifica um fator principal, devem-se considerar seus vínculos com outros fatores que, não sendo variáveis distintivas de comparação, afetam os processos sociais por conta das relações multicausais que existem entre as instituições internas e externas ao campo (Ostrom, 2009). Como não é possível explorar todas essas relações em um artigo, esta seção destaca apenas os fatores que se mostraram mais relevantes aos processos de dissociação identificados anteriormente.

O primeiro é a resistência dos atores às pressões isomórficas. A capacidade de ação coletiva e de reação dos movimentos agroecológicos à institucionalização do modelo privado de auditoria criou as condições para o reconhecimento de outros sistemas de verificação da qualidade orgânica. Destaca-se aqui a relevância da Articulação Nacional de Agroecologia (ANA) como organização que se estabeleceu como um movimento-rede coordenando as reações (Petersen et al., 2013). Isto foi favorecido pela janela de oportunidade aberta pela presença de uma coalizão de centro-esquerda à frente do governo federal, a qual incluiu atores oriundos dos movimentos sociais rurais e das organizações agroecológicas. Soma-se a isso a demanda crescente por alimentos orgânicos no Brasil, de modo que qualquer pressão mais forte do campo em direção à homogeneização era freada pela necessidade de ampliar a oferta. Assim, mesmo quando determinados atores (gestores, certificadoras, empresas e supermercados) tentaram impor regras mais rígidas, eles se viram obrigados a recuar para garantir, inclusive, o próprio acesso a produtos certificados. Destaca-se aqui o poder de negociação do OPAC Ecovida que, sozinho, responde por um quarto de todos os registros de produtores orgânicos do Brasil. Em virtude da sua própria heterogeneidade interna, a Ecovida sempre advogou em prol de regras adaptáveis aos contextos locais. Portanto, o próprio "modelo Ecovida" dificilmente seria indutor de isomorfismo.

O segundo fator de dissociação é a ambiguidade e heterogeneidade do ambiente institucional construído no Brasil (Niederle et al., 2020). A ambiguidade institucional está associada a três características das instituições: a) elas são incompletas, pois não podem controlar todas as práticas sociais; b) duas ou mais instituições podem coexistir e oferecer soluções diferentes para o mesmo problema, o que cria conflito; e c) os atores podem interpretar a mesma regra de maneira diferente quando as traduzem nas suas práticas (Ostrom, 2009; Boxenbaum \& Jonsson, 2017; Mahoney \& Thelen, 2009). Em virtude disso, ao invés de homogeneização, a difusão da certificação participativa se tornou fonte de diversidade. A título de exemplo pode-se notar que, embora tenha forçado a adoção de natureza jurídica formal - o que implica em respeitar a legislação sobre associações (Código Civil, art. 53 a 61) -, a pressão do Estado para registro dos OPACs repercutiu na criação de novas estruturas. Organizações formais (Coceargs) e informais (Rede Ecovida) previamente existentes tiveram que se reorganizar para comportar um OPAC no seu interior, mas isto apenas acentuou a diversidade.

Por sua vez, a heterogeneidade institucional está associada à existência de dispositivos normativos múltiplos e contraditórios, os quais são manejados pelas organizações para se dissociar de modelos inadequados às suas características. Com efeito, ao invés de replicar o "modelo Ecovida", os demais OPACs encontraram alternativas institucionais para desenvolver estruturas e condutas relativamente singulares. A "quase auditoria" criada pela Coceargs poderia ser interpretada a partir da ideia de dissociação como "dissimulação", ou seja, quando se adota apenas formalmente uma estrutura sem alterar efetivamente as práticas (Arvidson \& Lyon, 2014). O OPAC Rama criou um sistema de verificação intergrupos que, na prática, dispensa a comissão de verificação e a visita cruzada. Outro exemplo é o modo como a Rede Ecovida fundiu a assembleia do OPAC com a plenária de núcleos, de modo que, geralmente, o coordenador do núcleo da Rede é o representante da comissão de verificação do OPAC. Interessante notar, todavia, que estes casos não revelam uma tentativa dos OPACs de ocultar suas "verdadeiras práticas". Essas dissociações são conhecidas pelos demais atores do campo, incluindo o próprio Mapa, que é o órgão que audita os OPACs. O 
que se nota é um trabalho de mudança institucional gradual que pode tanto implicar em alterações nas condutas dos OPACs como na alteração das normas para reconhecer à realidade das práticas existentes (vide Figura 1, acima).

Finalmente, o terceiro fator que se mostrou relevante para entender os processos de dissociação identificados na pesquisa consiste nas dinâmicas internas de poder em cada organização. A construção dos OPACs tem por princípio moral e legal uma concepção de "poder compartilhado". Como destaca o Art. 69, § 2 , da IN 19/2009, "A participação referese à efetiva atuação dos membros nas ações do SPG, ao poder compartilhado nas decisões e pela responsabilidade na garantia da qualidade orgânica resultante do processo." No entanto, como vimos acima, esses organismos diferem entre eles no que tange ao modo como as decisões são tomadas e implementadas. Além da conformação dos espaços de participação e decisão, uma variável-chave aqui é a atuação dos técnicos. Nas situações em que esta é mais diretiva (Coceargs e Litoral Norte), seria factível imaginar, como propõem Dimaggio \& Powell (1983), uma maior tendência ao isomorfismo normativo. De fato, nos grupos, núcleos e OPACs mais novos, os técnicos se esforçam para traduzir aos demais os princípios que, nas suas interpretações, regem a agroecologia e a certificação participativa. Ao longo deste processo, eles destacam a necessidade de cada OPAC encontrar soluções adequadas às suas condições, promovendo diferenciação. No entanto, eles exercem certa pressão isomórfica dentro dos OPACs, sobretudo quando trabalham para que os grupos adotem condutas relativamente similares. Este resultado expõe o problema já mencionado da coexistência entre processos de isomorfismo e dissociação, o qual merecerá atenção em pesquisas futuras.

\section{Considerações finais}

Um dos pilares centrais da teoria do isomorfismo institucional é a ideia de que, "uma vez que um campo se torne bem estabelecido, há um impulso inexorável em direção à homogeneização." (Dimaggio \& Powell, 1983). Nossos resultados sugerem que esta é uma conclusão equivocada para explicar o que ocorreu até agora com a certificação participativa de produtos orgânicos no Brasil. O que identificamos foi a predominância de processos de dissociação que levaram à crescente diferenciação das organizações. Em virtude disso, rejeitamos a hipótese inicial que apontava para a "cópia" do "modelo original" da Ecovida, o qual orientou a construção da legislação brasileira. Ao mesmo tempo, já buscando identificar quais são os fatores que produzem a diferenciação, o artigo apontou para a importância de observar a ambiguidade e a heterogeneidade do ambiente institucional, a capacidade de agência dos atores sociais para resistir às pressões isomórficas e as dinâmicas internas de poder que estão, em alguma medida, relacionadas à participação social.

No entanto, uma das questões que emergiram ao final da pesquisa diz respeito à maturidade desse campo organizacional. Alguém poderia argumentar que este não é um campo "bem estabelecido" e que, portanto, esta seria a razão fundamental para a diversidade atualmente verificada. Algumas entrevistas efetivamente mencionaram 0 surgimento de constrangimentos institucionais cada vez mais fortes nos últimos anos, os quais estariam associados principalmente ao aumento das demandas burocráticas do Mapa. No caso do OPAC Ecovida, isto implicou, inclusive, na criação, em 2018, de um sistema informatizado para gestão dos documentos, o que repercute em uma pressão (mediada pelos técnicos) para que os grupos e núcleos padronizem determinadas práticas e rotinas técnicas. O mesmo também está em curso no OPAC Rama. Essas mudanças ocorrem paralelamente à desestruturação dos espaços de governança participativa, o que, por sua vez, tem efeitos na capacidade dos atores em reagir às novas imposições do Estado.

Desde 2016, como decorrência das mudanças que se processaram no campo políticoinstitucional brasileiro, em particular a ascensão ao poder de uma nova coalizão política, um conjunto de mudanças institucionais tem impactado diversos setores, dentre os quais, a agricultura. No caso específico da produção orgânica, três mudanças merecem destaque. Primeiro, o novo governo extinguiu a CNPOrg, dificultando a articulação das organizações 
agroecológicas e o diálogo delas com o Estado. Segundo, algumas políticas públicas que catalisaram o desenvolvimento dos OPACs têm sido desmanteladas, tais como os programas de assistência técnica e compras públicas (Niederle et al., 2019). Finalmente, mudanças organizacionais no interior do Mapa transferiram a certificação dos orgânicos para dentro do setor que se ocupa do controle sanitário dos produtos agropecuários, o qual atua com uma lógica de fiscalização distinta daquela que prevalece na certificação participativa.

Em virtude disso, algumas lideranças históricas do movimento agroecológico estão recolocando a discussão sobre a pertinência da certificação, retomando elementos da crítica dos anos 1990. Segundo eles, por mais que seja participativa, a certificação continua sendo um mecanismo de controle que restringe as possibilidades de transição agroecológica. Esta crítica abre uma agenda de pesquisa para o futuro, haja vista que ela pode levar a uma nova trajetória de "dissociação" institucional. Assim como ocorreu em outros países, os produtores podem optar por recrudescer as críticas à certificação oficial, inclusive a participativa, com vistas a se diferenciar por meio de outros sistemas de diferenciação qualitativa. O maior risco é voltar a assumir uma posição periférica no campo social, sem capacidade de intervir na produção das normas e, ao mesmo tempo, ser excluídos dos canais de comercialização mais convencionais - vide o que ocorreu com a Nature \& Progrés, organização francesa de certificação participativa que analisamos em outro momento (Niederle et al., 2020).

Estaríamos, portanto, na eminência de um processo de homogeneização? Para finalizar cabe um comentário adicional acerca das contribuições deste artigo. Dimaggio \& Powell (1983) nunca explicaram de maneira convincente o que seria um campo "bem estabelecido". Quais são as condições para afirmar que o campo está maduro o suficiente para avaliar se houve isomorfismo? Autores mais contemporâneos têm argumentado que a estabilidade institucional é uma condição mais precária e problemática do que a maioria das teorias reconhece (Greenwood et al., 2017; Thévenot, 2001). Com vistas a não se diluir, o próprio campo é continuamente objeto de reinstitucionalização e parece ser isso o que está ocorrendo com a certificação dos orgânicos neste momento. A experiência histórica mostrou que mesmo nos momentos em que as pressões isomórficas foram mais fortes, como nos anos 1990, quando o país importou o modelo internacional de auditoria privada, as organizações do movimento agroecológico foram hábeis para encontrar mecanismos de dissociação que repercutem na diversidade institucional atual. Investigar como este processo se desenvolverá daqui em diante também faz parte da agenda de pesquisa.

\section{Referências}

Åberg, P. (2013). Managing expectations, demands and myths: Swedish study associations caught between civil society, the state and the market. Voluntas, 24(3), 537-558.

Allen, P., \& Kovach, M. (2000). The capitalist composition of organic: the potential of markets in fulfilling the promise of organic agriculture. Agriculture and Human Values, 17(3), 221-232.

Arvidson, M., \& Lyon, F. (2014). Social impact measurement and non-profit organisations: Compliance, resistance, and promotion. Voluntas, 25(4), 869-886.

Beckert, J. (2010). Institutional isomorphism revisited: convergence and divergence in institutional change. Sociological Theory, 28(2), 150-166.

Boström, M. (2006). Regulatory credibility and authority through inclusiveness: standardization organizations in cases of eco-labelling. Organization, 13(3), 345-367.

Boxenbaum, E., \& Battilana, J. (2005). Importation as innovation: transposing managerial practices across fields. Strategic Organization, 3(4), 355-383.

Boxenbaum, E., \& Jonsson, S. (2017). Isomorphism, diffusion and decoupling: concept evolution and theoretical challenges. In R. Greenwood, C. Oliver, T. Lawrence \& R. Meyer (Eds.), The Sage Handbook of Institutional Institutionalism (2nd ed.). London: Sage.

Buck, D., Getz, C., \& Guthman, J. (1997). From farm to table: the organic vegetable commodity chain of Northern California. Sociologia Ruralis, 37(1), 3-20. 
Caldas, N. V., Anjos, F. S., Bezerra, A. J. A., \& Criado, E. A. (2012). Certificação de produtos orgânicos: obstáculos à implantação de um sistema participativo de garantia na Andaluzia, Espanha. Revista de Economia e Sociologia Rural, 50(3), 455-472.

Cruz, F. T., Ramos, L., Fruhauf, W. \& Bohrer, S. (2016). Agroecologia e relações de proximidade entre produtores e consumidores: a experiência dos produtores da Rede Agroecológica Metropolitana (RAMA)/RS. In: F. Cruz, A. Matte \& S. Schneider. (Ed.). Produção, Consumo e Abastecimento de Alimentos: desafios e novas estratégias. (pp. 215-224). Porto Alegre: UFRGS.

Dimaggio, P., \& Powell, W. (1983). The iron cage revisited: institutional isomorphism and collective rationality in organizational fields. American Sociological Review, 48(2), 147-160.

Ellersgaard, C., Larsen, A., \& Munk, M. (2013). A very economic elite: the case of the Danish top CEOs. Sociology, 47(6), 1051-1071.

Fligstein, N., \& McAdam, D. (2012). A theory of fields. Oxford: Oxford University Press.

Forni, P., \& Leite, L. (2006). El desarrollo y legitimación de las organizaciones del tercer sector en la Argentina: hacia la definición de un isomorfismo periférico. Sociologias, 8(16), 368-375.

Fouilleux, E. (2013). Normes transnationales de développement durable. Formes et contours d'une privatisation de la délibération. Gouvernement et Action Publique, 2(1), 93-119.

Fouilleux, E., \& Loconto, A. (2017). Voluntary standards, certification, and accreditation in the global organic agriculture field: a tripartite model of techno-politics. Agriculture and Human Values, 34(1), 114.

Greenwood, R., Oliver, C., Lawrence, T., \& Meyer, R. (Eds.). (2017). The Sage Handbook of Institutional Institutionalism (2nd ed.). London: Sage.

Greenwood, R., Raynard, M., Kodeih, F., Micelotta, E., \& Lounsbury, M. (2011). Institutional complexity and organizational responses. The Academy of Management Annals, 5(1), 317-371.

Hannan, M., \& Freeman, J. (1977). The population ecology of organizations. American Journal of Sociology, 82(5), 929-964.

Hassenteufel, P. (2008). Sociologie politique: I'action publique (2nd ed.). Paris: Armand Colin.

Hatanaka, M., Bain, C., \& Busch, L. (2005). Third-party certification in the global agrifood system. Food Policy, 30(3), 354-369.

Isaguirre, K., \& Passos, M. (2013). Certificação na prática: a Rede Ecovida e os desafios da implementação de sistemas participativos de garantia. In P. Niederle, L. Almeida \& F. Vezzani (Eds.), Agroecologia: práticas, mercados e políticas para uma nova agricultura (pp. 362-387). Curitiba: Kairós.

Jarvis, D. (2014). Policy transfer, neo-liberalism or coercive institutional isomorphism? Explaining the emergence of a regulatory regime for quality assurance in the Hong Kong higher education sector. Policy and Society, 33(3), 237-252.

Lemeilleur, S., \& Allaire, G. (2018). Système participatif de garantie dans les labels du mouvement de l'agriculture biologique: une réappropriation des communs intellectuels. Économie Rurale (Paris), 365(365), 7-27.

Loconto, A., \& Hatanaka, M. (2018). Participatory Guarantee Systems: alternative ways of defining, measuring, and assessing sustainability. Sociologia Ruralis, 58(2), 412-432.

Loconto, A., Poisot, A., \& Santacoloma, P. (2016). Innovative markets for sustainable agriculture. Roma: FAO.

Mahoney, J., \& Thelen, K. (eds.). (2009). Explaining institutional change: ambiguity, agency, and power. Cambridge: Cambridge University press.

Medaets, J.-P., \& Cechin, A. D. (2019). A ação coletiva como facilitador da inovação no manejo orgânico: o caso do Sistema Participativo de Garantia. Estudos Sociedade e Agricultura, 27(1), 118-136.

Medaets, J.-P., Fornazier, A., \& Thomé, K. (2020). Transition to sustainability in agrifood systems: Insights from Brazilian trajectories. Journal of Rural Studies, 76, 1-11.

Meyer, J. W., \& Rowan, B. (1977). Institutionalized organizations: formal structure as myth and ceremony. American Journal of Sociology, 83(2), 340-363.

Niederle, P. (2014). Os agricultores ecologistas nos mercados para alimentos orgânicos: contramovimentos e novos circuitos de comércio. Sustentabilidade em Debate, 5, 79-96.

Niederle, P., \& Radomsky, G. (2017). Quem governa por dispositivos? A produção das normas e padrões para os alimentos orgânicos no Brasil. Tomo, 30, 227-265.

Niederle, P., \& Wesz Junior, V. (2018). As novas ordens alimentares. Porto Alegre: UFRGS. 
Niederle, P., Grisa, C., Picolotto, E., \& Soldera, D. (2019). Narrative disputes over family-farming public policies in Brazil: conservative attacks and restricted countermovements. Latin American Research Review, 54(3), 707-720. http://dx.doi.org/10.25222/larr.366

Niederle, P., Loconto, A., Lemeilleur, S., \& Dorville, C. (2020). Social movements and institutional change in organic food markets: Evidence from participatory guarantee systems in Brazil and France. Journal of Rural Studies, 78, 282-291. http://dx.doi.org/10.1016/j.jrurstud.2020.06.011

Ostrom, E. (2009). Understanding institutional diversity. Princeton: Princeton University Press.

Peci, A. (2006). A nova teoria institucional em estudos organizacionais: uma abordagem crítica. Cadernos EBAPE.BR, 4(1), 1-12.

Petersen, P., Mussoi, E., \& Dal Soglio, F. (2013). Institutionalization of the agroecological approach in Brazil: advances and challenges. Agroecology and Sustainable Food Systems, 37(1), 103-114.

Radaelli, C. (2000). Policy transfer in the European Union: institutional isomorphism as a source of legitimacy. Governance: An International Journal of Policy, Administration and Institutions, 13(1), 25-43.

Radomsky, G. F. W. (2015). O poder do selo. Porto Alegre: UFRGS.

Ramanath, R. (2009). Limits to institutional isomorphism: examining internal processes in NGOgovernment interactions. Nonprofit and Voluntary Sector Quarterly, 38(1), 51-76.

Rosset, P., \& Altieri, M. (1997). Agroecology versus input substitution: a fundamental contradiction of sustainable agriculture. Society \& Natural Resources, 10(3), 283-295.

Thévenot, L. (2001). Pragmatic regimes governing the engagement with the world. In T. Schatzki, K. Knorr-Cetina \& E. Von Savigny (Eds.), The practice turn in contemporary theory (pp. 56-73). London: Routledge.

Submetido: 4/Jun./2019.

Aceito: $21 /$ Jun./2020

Classificação JEL: A14, Q10, Q18. 